\title{
A Novel Natural Product Compound Enhances cAMP-Regulated Chloride Conductance of Cells Expressing CFTR $\Delta$ F508
}

\author{
Ana C. V. deCarvalho, ${ }^{1}$ Chi P. Ndi, ${ }^{2}$ Apollinaire Tsopmo, ${ }^{2}$ Pierre Tane, ${ }^{2}$ Johnson Ayafor, ${ }^{2}$ \\ Joseph D. Connolly, ${ }^{3}$ and John L. Teem ${ }^{1}$ \\ ${ }^{1}$ Department of Biological Science, Florida State University, Tallahassee, FL, USA \\ ${ }^{2}$ Department of Chemistry, Faculty of Science, University of Dschang, Dschang, Cameroon \\ ${ }^{3}$ Department of Chemistry, University of Glasgow, Glasgow, UK \\ Accepted January 25, 2002
}

\begin{abstract}
Background: Cystic fibrosis (CF) results from mutations in the cystic fibrosis transmembrane conductance regulator (CFTR) gene, which encodes a chloride channel localized at the plasma membrane of diverse epithelia. The most common mutation leading to $C F, \Delta F 508$, occurs in the first nucleotide-binding domain (NBD 1) of CFTR. The $\Delta$ F508 mutation disrupts protein processing, leading to a decreased level of mutant channels at the plasma membrane and reduced transepithelial chloride permeability. Partial correction of the $\Delta \mathrm{F} 508$ molecular defect in vitro is achieved by incubation of cells with several classes of chemical chaperones, indicating that further investigation of novel small molecules is warranted as a means for producing new therapies for CF.

Materials and Methods: The yeast two-hybrid assay was used to study the effect of CF-causing mutations on the ability of NBD 1 to self-associate and form dimers. A yeast strain demonstrating defective growth as a result of impaired NBDl dimerization due to $\triangle \mathrm{F} 508$ was used as a drug discovery bioassay for the identification of plant natural product compounds restoring mutant NBDI interaction. Active compounds were purified and the chemical structures determined. The purified compounds were tested in epithelial cells expressing CFTR $\Delta$ F508
\end{abstract}

and the resulting effect on transepithelial chloride permeability was assessed using short-circuit chloride current measurements.

Results: Wild-type NBDI of CFTR forms homodimers in a yeast two-hybrid assay. CF-causing mutations within NBD 1 that result in defective processing of CFTR $(\Delta F 508$, $\Delta \mathrm{I} 507$, and S549R) disrupted NBDl interaction in yeast. In contrast, a CF-causing mutation that does not impair CFTR processing (G551D) had no effect on NBDl dimerization. Using the yeast-based assay, we identified a novel limonoid compound (TS3) that corrected the $\Delta$ F508 NBD 1 dimerization defect in yeast and also increased the chloride permeability of Fisher Rat Thyroid (FRT) cells stably expressing CFTR $\Delta$ F508.

Conclusion: The establishment of a phenotype for the $\Delta$ F508 mutation in the yeast two-hybrid system yielded a simple assay for the identification of small molecules that interact with the mutant NBDI and restore dimerization. The natural product compound identified using the system (TS3) was found to increase chloride conductance in epithelial cells to an extent comparable to genistein, a known CFTR activator. The yeast system will thus be useful for further identification of compounds with potential for CF drug therapy.

\section{Introduction}

Cystic fibrosis (CF) is a lethal human genetic disease resulting from mutations in the cystic fibrosis transmembrane conductance regulator (CFTR) gene (1-3). The protein encoded by the CFTR gene is a cAMP-regulated chloride channel located in the apical membrane of epithelial cells in various tissues (4). CFTR is a member of the ABC transporter superfamily of proteins that are involved in translocation of a diverse set of substrates across biological membranes in both prokaryotes and eukaryotes (5). It has been proposed that a functional $A B C$ transporter has a minimal structural requirement of two membrane-spanning domains (MSDs) and two

Address correspondence and reprint requests to: John Teem, Department of Biological Science, Biounit-238, Florida State University, Tallahassee, Florida 32306, USA. Phone: (850) 644-5121; fax: (850) 644-0481; e-mail: teem@bio.fsu.edu cytosolic nucleotide binding domains (NBDs) that can be present in a single polypeptide or formed by a membrane-associated multiprotein complex (6).

The most common mutation causing CF is the in-frame deletion of a phenylalanine at position 508 $(\Delta \mathrm{F} 508)$ in the first nucleotide binding domain of CFTR (NBDl), occurring in $\sim 70 \%$ of CF chromosomes. The $\triangle \mathrm{F} 508$ mutation impairs processing of CFTR in the endoplasmic reticulum (ER), resulting in decreased levels of mature CFTR at the plasma membrane and defective cAMP-regulated chloride conductance in diverse epithelia. A large fraction of CFTR $\Delta$ F508 fails to fold into a native conformation, resulting in its retention by the ER-associated quality control and subsequent degradation with the participation of the cytoplasmic proteasome (7-11). In addition to the biosynthetic defect, the $\Delta \mathrm{F} 508$ mutation also affects the chloride channel function of CFTR, reducing the channel open probability $\left(P_{\mathrm{o}}\right)$ 
(12-14). Partial reversal of the processing defect resulting from $\Delta$ F508 can be achieved by altering conditions in which cultured cells expressing the mutant CFTR are incubated. For example, addition of glycerol in high concentration to the culture media $(15,16)$ or reduction of the cell culture incubation temperature (17) partially restore CFTR $\Delta$ F508 processing. Additionally, several CFTR activators have been developed that can enhance activity of the mutant chloride channel at the plasma membrane $(18,19)$.

The $\Delta$ F508 mutation is thought to affect the folding of the NBDl domain polypeptide $(20,21)$, leading to defective processing and function of the mutant CFTR $\Delta$ F508 protein. The precise effect of $\Delta \mathrm{F} 508$ on NBDl structure is unknown because a crystal structure of CFTR NBDl is currently unavailable. Dimerization of NBDs has been observed for the subunits of bacterial ABC transporters HisP and MalK (22-25), and for the ER and peroxisomal localized ABC transporters (26). Thus, dimerization of CFTR NBDs may similarly occur, and the $\Delta$ F508 mutation may interfere with NBDl folding such that dimerization is defective.

Using the yeast two-hybrid system, we have established that CFTR NBDI is able to interact with itself in vivo, and that the $\Delta \mathrm{F} 508$ mutation impairs this interaction. We have used the yeast two-hybrid assay in a drug screening format to identify a novel limonoid compound that reverses the $\Delta \mathrm{F} 508$ dimerization defect in yeast and promotes increased cAMP-stimulated chloride current from mammalian cells expressing CFTR $\Delta$ F508. The identification of compounds that specifically target and rescue CFTR $\Delta$ F508 could lead to the development of a therapy for CF.

\section{Materials and Methods}

Plasmid Construction and Yeast Strains

The plasmid pSwick-CFTR containing the fulllength wild-type CFTR cDNA was obtained from M. Welsh (University of Iowa) and amplified by the polymerase chain reaction (PCR) with the appropriate oligonucleotide primers to generate a DNA segment corresponding to CFTR NBDI and upstream linker region, T351-F650. The T351-F650 segment was cloned in-frame into the carboxy-terminus of the GAL4 DNA-binding domain on a yeast plasmid pBDGAL4 (Stratagene Cloning Systems, La Jolla, CA, USA). The resulting plasmid (pBDNBDl) contains a fusion protein consisting of the GAL4 DNA binding domain fused to CFTR NBDI (T351-F650) expressed under the control of the yeast ADH1 promoter and also contains the yeast selectable marker TRPl and the $2 \mu$ origin of replication. The same segment of CFTR NBDl was also cloned in-frame into the GAL 4 activation domain on pADGAL4 (with the yeast selectable marker LEU2 and $2 \mu$ origin) to produce pADNBDl. Both plasmids pBDNBDl and pADNBDI were introduced by transformation into yeast strain YGR-2 (Hybrizap Two Hybrid Cloning Kit, Stratagene), genotype: Mat $\alpha$, ura3-52, his3-200, ade2-101, lys2-801, trpl-901, leu2-3, 112, gal4-542, gal80-538, LYS2::UAS $\mathrm{GAL1}-\mathrm{TATA}_{\mathrm{GAL1}}$-HIS3

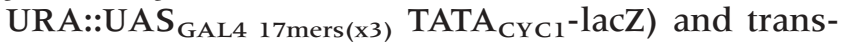
formants were selected on selective media lacking tryptophan and leucine to produce the yeast strain YRG2-WT. Plasmids identical to pBDNBD1 and pADNBDl, but containing CF-causing mutations $(\Delta \mathrm{F} 508, \Delta \mathrm{I} 507, \mathrm{~S} 549 \mathrm{R}$, and G55 1D) were similarly constructed (producing pBD $\Delta \mathrm{F}, \mathrm{pAD} \Delta \mathrm{F}, \mathrm{pBD} \Delta \mathrm{I} 507$, pAD $\triangle 1507$, pBDS549R, pADS549R, pBDG551D, pADG551D). Plasmids pBD $\Delta \mathrm{F}$ and $\mathrm{pAD} \Delta \mathrm{F}$ were introduced by transformation into yeast strain YGR-2 to produce yeast strain YRG2- $\Delta$ F. Other yeast strains expressing GAL4/CFTR NBDI fusion proteins containing CF-causing mutations were constructed by transformation with the cognate pBDNBDl and pADNBD1 derivatives. The YRG-2 control strain used in Figure 4 contained pBDGAL4 (lacking CFTR NBDl sequences) and pADNBDl. The DNA structure of the constructs was confirmed by DNA sequence analysis.

\begin{tabular}{|l|l|}
\hline pBDGAL 4 & pADGAL4 \\
\hline NBD1 WT & NBD1 WT \\
\hline NBD1 $\triangle$ F508 & NBD1 $\Delta$ F508 \\
\hline NBD1 $\Delta$ I507 & NBD1 $\Delta$ I507 \\
\hline NBD1 S549R & NBD1 S549R \\
\hline NBD1 G551D & NBD1 G551D \\
\hline P53 & NBD1 WT \\
\hline NBD1 WT & T-antigen \\
\hline
\end{tabular}

A)

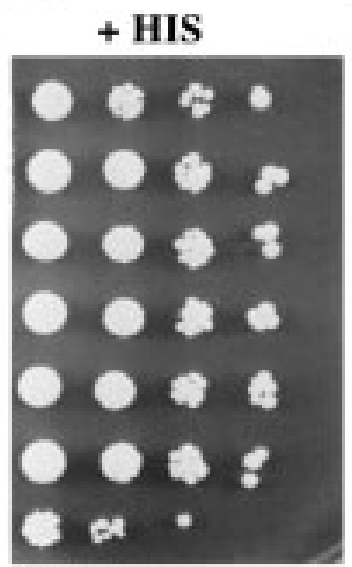

B)

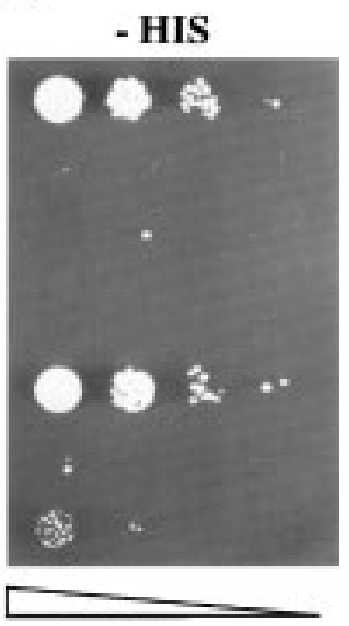

Fig. 1. Effect of CF mutations on NBD1 interaction in the yeast two-hybrid system. The yeast strain YRG-2 was cotransformed with the pBDNBDl and pADNBDl plasmids as indicated. pADNBDl and pBDNBDl were co-expressed with pBDGal4 p53 and pADGal4 T-antigen, respectively, as controls. Equal aliquots of serial dilutions of each yeast strain were plated on -Leu -Trp medium (A) and on -Leu -Trp -His selective medium containing $5 \mathrm{mM}$ AT (B). Triangles indicate increasing dilution of each culture. Plates were incubated for 3 days at $30^{\circ} \mathrm{C}$. 


\section{Yeast Two-Hybrid Assay}

YRG-2 yeast strains expressing the pADNBDl and pBDNBDl variants were plated on selective medium lacking histidine as described by the supplier (Stratagene), supplemented with 1.5-5 $\mathrm{mM}$ 3-amino-1,2,4-triazole (AT) and incubated at $30^{\circ} \mathrm{C}$ for 3 days.

\section{Bioassay-Directed Fractionation}

Leaves of Trichilia sp. c.f. rubescens Oliv. were collected from Korup reserve, South West Province of Cameroon. Air-dried powdered leaves (2.7 kg) were macerated in acetone $(8 \mathrm{l})$ at room temperature for $3 \times 2$ days. Filtration and vacuum concentration led to a dark greenish extract (154 g). This extract was dissolved in a mixture of $\mathrm{H}_{2} \mathrm{O}-\mathrm{MeOH}$ (9:1) and subsequently extracted with hexane and $\mathrm{CH}_{2} \mathrm{Cl}_{2}$ to afford $47.5 \mathrm{~g}$ and $42.5 \mathrm{~g}$ of the hexanesoluble fraction and $\mathrm{CH}_{2} \mathrm{Cl}_{2}$-soluble fraction, respectively. Vacuum liquid chromatography on $\mathrm{SiO}_{2}$ of the $\mathrm{CH}_{2} \mathrm{Cl}_{2}$ extract (which contained the bioactivity) eluted with gradients of EtOAc in hexane led to five main fractions (F1-F5) of increasing polarity. Only fractions F3 and F4 yielded positive results in the yeast two-hybrid bioassay. F3 (1.2 g) eluted with hexane-EtOAc (8:2) was then passed through a silica gel column using $\mathrm{CH}_{2} \mathrm{Cl}_{2}$ to give a mixture that was further purified on chromatotron using $\mathrm{Me}_{2} \mathrm{CO}-\mathrm{CH}_{2} \mathrm{Cl}_{2}$ (2:98) to give TS2 (80 $\mathrm{mg})$ and a mixture of unresolved compounds. F4 (0.9 g), also eluted with hexaneEtOAc (8:2), was purified in the same way as fraction F3 to yield TS 1 (40 mg) and TS3 (133 mg). An additional purification of TS 1 and TS3 by gel permeation through Sephadex LH-20 (to remove chlorophyll) was required to obtain pure analytical samples.

\section{Experimental Procedures for Structure Determination}

Melting points were recorded with a kohfler hot stage 277938 and are uncorrected. Optical rotations were measured on an AA Series automatic polarimeter POLAAR-2000, while the IR spectra were recorded on a JASCO FT-IR-410 spectrophotometer. ${ }^{1} \mathrm{H}$ NMR (400 MHz) and ${ }^{13} \mathrm{C}$ NMR (100 MHz) spectra were recorded in $\mathrm{CDCl}_{3}$ on BRUKER DPX-400 spectrometer. The chemical shifts $(\delta)$ are reported in parts per million $(\mathrm{ppm})$ relative to chloroform signals as reference $\left(\delta_{\mathrm{H}}=7.26\right.$ and $\delta_{\mathrm{C}}=$ 77.0) and coupling constants ( $J$ values) are given in Hertz. ${ }^{1} \mathrm{H}^{-1} \mathrm{H}$ COSY, NOE's, HMBC, and HMQC experiments were recorded with gradient enhancements using sine-shaped gradient pulses. Mass spectra were recorded in the positive EI mode on a JEOL JMS-700 instrument. Column chromatography, run on Merck Si gel 60, and gel permeation chromatography on Sephadex LH-20 were used for isolation and purification. TLC were carried out on silica gel $60 \mathrm{~F}_{254}$ (Merck) precoated plates and spots visualized by spraying with $50 \% \quad \mathrm{H}_{2} \mathrm{SO}_{4}$ solution followed by heating, or with UV lamp (254 and $366 \mathrm{~nm}$ ).

\section{Spectroscopic Analysis of Limonoid Compounds}

TS I was obtained as white crystals in hexane, $\operatorname{mp~} 292-294^{\circ} \mathrm{C},[\alpha]_{\mathrm{D}}{ }^{25}+32.5^{\circ}\left(\mathrm{c} 0.6, \mathrm{CHCl}_{3}\right)$. The EIMS of TS 1 gave a molecular ion peak at $\mathrm{m} / \mathrm{z} 438$ compatible with molecular formula $\mathrm{C}_{26} \mathrm{H}_{30} \mathrm{O}_{6}$. The TS I IR spectrum showed peaks at $v_{\max } 3437$ and $1664 \mathrm{~cm}^{-1}$ attributed to hydroxyl group and enone moiety, respectively. The ${ }^{1} \mathrm{H}$ NMR spectrum for TS 1 (Table 1) showed proton signals at $\delta 7.36(\mathrm{~d}$, $J=1.6 \mathrm{~Hz}), 7.13(\mathrm{~s})$, and $6.18(\mathrm{~d}, J=1.6 \mathrm{~Hz})$ which were attributed to a furan ring (27), while proton signals at $\delta 5.93(\mathrm{~d}, J=9.5 \mathrm{~Hz})$ and $7.08(\mathrm{~d}, J=$ 9.5 Hz) were attributed to $\mathrm{H}-2$ and $\mathrm{H}-3$, respectively. Many other proton signals were observed including four methyl groups between $\delta 1.41-0.80$. The ${ }^{13} \mathrm{C}$ NMR spectrum (Table 2 ) showed the presence of a carbonyl group at $\delta 200.8$, and carbon signals at $\delta 131.6$ and 151.9 were attributed to C-2 and $\mathrm{C}-3$, respectively. Four methyl signals were also observed between $\delta 22.5-17.8$. The COSY spectrum showed proton-proton correlations such as $\mathrm{H}-2$ to H-3; H-6 to H-5 and H-7; $\mathrm{H}-16$ to $\mathrm{H}-15$ and $\mathrm{H}-17$; $\mathrm{H}-11$ to $\mathrm{H}-12$; and $\mathrm{H}-22$ to $\mathrm{H}-23$. HMBC spectrum showed pertinent cross-correlation peaks between $\mathrm{H}-19$ and $\mathrm{C}-1, \mathrm{C}-5, \mathrm{C}-9$, and $\mathrm{C}-10 ; \mathrm{H}-29$ and $\mathrm{C}-3$, $\mathrm{C}-4, \mathrm{C}-5$, and C-28; as well as between $\mathrm{H}-11$ and $\mathrm{C}-8, \mathrm{C}-10, \mathrm{C}-12$, and $\mathrm{C}-13$. The structure of TS 1 was determined on the basis of all the above NMR data. The stereochemistry of TS 1 was determined with the aid of NOE's correlations as shown in Figure 3B. The coupling constants observed in the ${ }^{1} \mathrm{H}$ NMR spectrum were also very useful. The large coupling constant $(J=12.6 \mathrm{~Hz})$ between $\mathrm{H}-5$ and H-6 clearly showed that both protons were in trans position, and the smaller one $(J=3.8 \mathrm{~Hz})$ between H-6 and H-7 was indicative of their cis relationship. It is known that in such systems, H-5 is under the plane of the molecule, which automatically means that $\mathrm{H}-6$ is on the upper face of TS 1 .

TS2 was obtained as white crystals in hexane, $\operatorname{mp} 212-215^{\circ} \mathrm{C},[\alpha]_{\mathrm{D}}{ }^{25}+40.5^{\circ}\left(c 0.57, \mathrm{CHCl}_{3}\right)$. The EIMS of TS2 gave a molecular ion peak at $\mathrm{m} / \mathrm{z} 506$, compatible with the molecular formula $\mathrm{C}_{30} \mathrm{H}_{34} \mathrm{O}_{7}$. The TS2 IR spectrum showed peaks at 1720 (ester) and $1672 \mathrm{~cm}^{-1}$ (enone). The NMR data (Tables 1 and 2) of TS2 were closely related to those of TS 1 . Additional proton signals were observed in TS2 at $\delta 5.90,5.67$, and 2.00 in ${ }^{1} \mathrm{H}$ NMR spectrum; four additional carbon signals were observed in the ${ }^{13} \mathrm{C}$ NMR spectrum (Table 2 ) at $\delta 167.1,137.0,126.6$, and 19.2. HMBC correlation peak observed in TS2 between $\mathrm{H}-7$ and the carbonyl ( $\delta 167.1), \mathrm{C}-5, \mathrm{C}-6$, and C-8 indicated that the ester group was linked at C-7. Structure TS2 has thus been assigned on the basis of this spectral data. 
Table 1. ${ }^{1} \mathrm{H}$ NMR spectra data for compounds TS1-TS3 $\left(\mathrm{CDCl}_{3}, 400 \mathrm{MHz}\right) ; J$ values in hertz are given in parentheses

\begin{tabular}{|c|c|c|c|}
\hline $\mathbf{H}$ & TS1 & TS2 & TS3 \\
\hline 2 & $5.93(d, 9.5)$ & $5.97(d, 9.5)$ & $5.91(\mathrm{~d}, 9.6)$ \\
\hline 3 & $7.08(d, 9.5)$ & $7.09(\mathrm{~d}, 9.5)$ & $7.05(d, 9.6)$ \\
\hline 5 & $2.93(\mathrm{~d}, 12.6)$ & $2.92(\mathrm{~d}, 12.6)$ & $3.35, \mathrm{~s}$ \\
\hline 6 & $4.40(\mathrm{dd}, 12.6,3.8)$ & $4.47(\mathrm{dd}, 12.6,4.0)$ & - \\
\hline 7 & $3.95(\mathrm{~d}, 3.8)$ & $5.51(\mathrm{~d}, 4.0)$ & $4.75, \mathrm{~s}$ \\
\hline 11 & $3.81(\mathrm{dd}, 6.4,1.5)$ & $3.97(\mathrm{dd}, 6.4,1.4)$ & $3.6(\mathrm{dd}, 5.6,1.3)$ \\
\hline 12 & $1.94,1.88, \mathrm{~m}$ & $1.94,1.88, \mathrm{~m}$ & $1.95,1.78, \mathrm{~m}$ \\
\hline 15 & $3.43(\mathrm{dd}, 8.8,2.9)$ & $3.45(\mathrm{dd}, 8.8,3.0)$ & $3.30(\mathrm{dd}, 8.8,2.9)$ \\
\hline 16 & $2.20,1.90, \mathrm{~m}$ & $2.19,1.59, \mathrm{~m}$ & $2.22,1.88, \mathrm{~m}$ \\
\hline 17 & $2.60(\mathrm{dd}, 11.2,6.7)$ & $2.54(\mathrm{dd}, 11.3,6.5)$ & $2.60(\mathrm{dd}, 11.2,6.7)$ \\
\hline 18 & $0.80, \mathrm{~s}$ & $0.78, \mathrm{~s}$ & $0.78, \mathrm{~s}$ \\
\hline 19 & $1.41, \mathrm{~s}$ & $1.44, \mathrm{~s}$ & $1.41, \mathrm{~s}$ \\
\hline 21 & $7.13, \mathrm{~s}$ & $7.05, \mathrm{~s}$ & $7.12, \mathrm{~s}$ \\
\hline 22 & $6.18(d, 1.6)$ & $6.10,(d, 1.6)$ & $6.15(\mathrm{~d}, 1.6)$ \\
\hline 23 & $7.36(\mathrm{~d}, 1.6)$ & $7.35(\mathrm{~d}, 1.6)$ & $7.36(\mathrm{~d}, 1.6)$ \\
\hline 28 & $3.88,3.75(\mathrm{~d}, 7.3)$ & $3.80,3.59(\mathrm{~d}, 7.3)$ & $4.05,3.92(\mathrm{~d}, 7.2)$ \\
\hline 29 & $1.37, \mathrm{~s}$ & $1.39, \mathrm{~s}$ & $1.34, \mathrm{~s}$ \\
\hline 30 & $1.10, \mathrm{~s}$ & $1.30, \mathrm{~s}$ & $1.18, \mathrm{~s}$ \\
\hline $3^{\prime}$ & - & $2.00, \mathrm{~s}$ & - \\
\hline $4^{\prime}$ & - & $5.90,5.67(d, 2)$ & - \\
\hline
\end{tabular}

TS3 was obtained as white crystals in hexane, $\mathrm{mp}$ $260-262^{\circ} \mathrm{C},[\alpha]_{\mathrm{D}}{ }^{25}-40.5^{\circ}\left(\mathrm{c} 0.6, \mathrm{CHCl}_{3}\right)$. The EIMS for TS3 gave a molecular ion peak at $\mathrm{m} / \mathrm{z} 420$, compatible with molecular formula $\mathrm{C}_{26} \mathrm{H}_{28} \mathrm{O}_{5}$. The TS3 IR spectrum showed peaks at 1680 and $1634 \mathrm{~cm}^{-1}$. The NMR data (Tables 1 and 2) of TS3 were again closely related to those of TS 1 . The hydroxyl group present in the IR spectrum of TSI was absent in that of TS3, while additional $\mathrm{sp}^{2}$ carbon atoms appeared in the ${ }^{13} \mathrm{C}$ NMR spectrum of TS3 at $\delta 150.4$ and 100.7. This clearly showed that dehydration occurred in TS 1 to give TS3. The proposed structure was in agreement with correlations observed in COSY, NOE's, HMQC, and HMBC spectra.

\section{Cell Culture}

Fischer rat thyroid (FRT) cell lines stably expressing either CFTR or CFTR $\Delta$ F508 were a generous gift from M. Welsh (University of Iowa) (28). FRT cells were maintained at $37^{\circ} \mathrm{C}$ in a humidified, $5 \%$ carbon dioxide atmosphere. Growth medium was Coon's modification of Ham's F-12 (Sigma Chemical Co., St. Louis, MO, USA) supplemented with 5\% Fetal Bovine Serum (Summit Biotechnology, Ft. Collins, CO, USA) and $100 \mathrm{U} / \mathrm{ml}$ of penicillin $\mathrm{G}$ sodium, $100 \mathrm{U} / \mathrm{ml}$ of streptomycin sulfate, and
$0.25 \mu \mathrm{g} / \mathrm{ml}$ of amphotericin B (GibcoBRL, Grand Island, NY, USA).

\section{Electrophysiology}

For functional studies, FRT cell lines stably expressing CFTR variants were plated at $2.5 \times 10^{5} \mathrm{cells} / \mathrm{cm}^{2}$ on Millicell-HA cell culture inserts (pore size $0.45 \mu \mathrm{m}$, Millipore Co., Bedford, MA, USA) and incubated under the conditions described above. Transepithelial resistance was monitored daily (Millicell Electrical Resistance System, Millipore) and were typically higher than $3000 \Omega / \mathrm{cm}^{2}$ after 4 days. FRT monolayers were mounted on modified Ussing chambers (Jim's Instruments, Iowa City, IA, USA) and continually gassed with $\mathrm{O}_{2}$. Temperature was maintained at $37^{\circ} \mathrm{C}$. Transepithelial chloride gradient was imposed by bathing the basolateral surface containing (in $\mathrm{mM}$ ): $135 \mathrm{NaCl}, 1.2 \mathrm{CaCl}_{2}$, $1.2 \mathrm{MgCl}_{2}, 2.4 \mathrm{~K}_{2} \mathrm{HPO}_{4}, 0.6 \mathrm{KH}_{2} \mathrm{PO}_{4}, 10 \mathrm{HEPES}$ and 10 dextrose, pH 7.4, and the apical surface with a similar solution, except that $135 \mathrm{mM}$ sodium gluconate replaced the $135 \mathrm{mM} \mathrm{NaCl}$, bringing the chloride concentration to $4.8 \mathrm{mM}$. Under these conditions, the chloride resting potential, according to Nernst equation is $90 \mathrm{mV}$. The potential difference and the fluid resistance between the potential sensing electrodes were compensated. The transepithelial voltage was 
Table 2. ${ }^{13} \mathrm{C}$ NMR spectra data for compounds TS1-TS3 $\left(\mathrm{CDCl}_{3}, 100 \mathrm{MHz}\right)$

\begin{tabular}{|c|c|c|c|}
\hline C & TS1 & TS2 & TS3 \\
\hline 1 & 200.8 & 200.6 & 199.5 \\
\hline 2 & 131.6 & 131.6 & 132.5 \\
\hline 3 & 151.9 & 152.0 & 149.9 \\
\hline 4 & 43.0 & 43.1 & 44.2 \\
\hline 5 & 48.8 & 51.0 & 54.9 \\
\hline 6 & 73.7 & 71.5 & 150.4 \\
\hline 7 & 74.5 & 75.5 & 100.7 \\
\hline 8 & 45.5 & 45.2 & 41.1 \\
\hline 9 & 65.3 & 64.9 & 66.9 \\
\hline 10 & 47.8 & 47.8 & 47.5 \\
\hline 11 & 61.0 & 60.7 & 59.0 \\
\hline 12 & 35.9 & 35.7 & 34.5 \\
\hline 13 & 41.8 & 41.8 & 41.5 \\
\hline 14 & 69.9 & 68.7 & 72.0 \\
\hline 15 & 55.9 & 55.6 & 53.8 \\
\hline 16 & 31.8 & 31.5 & 31.2 \\
\hline 17 & 39.7 & 39.2 & 40.5 \\
\hline 18 & 21.4 & 21.5 & 19.0 \\
\hline 19 & 17.8 & 17.7 & 19.2 \\
\hline 20 & 123.9 & 123.4 & 123.5 \\
\hline 21 & 139.8 & 139.7 & 139.8 \\
\hline 22 & 111.6 & 111.2 & 111.3 \\
\hline 23 & 143.1 & 143.3 & 143.3 \\
\hline 28 & 80.1 & 79.9 & 81.3 \\
\hline 29 & 21.9 & 22.0 & 21.6 \\
\hline 30 & 22.5 & 23.1 & 24.0 \\
\hline $1^{\prime}$ & - & 167.1 & - \\
\hline $2^{\prime}$ & - & 137.0 & - \\
\hline $3^{\prime}$ & - & 19.2 & - \\
\hline $4^{\prime}$ & - & 126.6 & - \\
\hline
\end{tabular}

clamped to zero (Voltage Clamp Channel Module, model 558C-5, Dept. of Bioengineering, University of Iowa), transepithelial resistance was monitored by recording of current deflections in response to 2-sec pulse of 1-5 mV every 50 sec. The short circuit currents were recorded continuously on a charter recorder (Model SR6335, Western Graphtec, Inc., Irvine, CA, USA). After a stable baseline current was observed (usually within less than $10 \mathrm{~min}$ ), the channel was activated with CAMP agonists and the current reflecting the flow of $\mathrm{Cl}^{-}$promoted by its concentration gradient $\left(I_{\mathrm{sc}}\right)$ was recorded as downward deflection. The $I_{\mathrm{sc}}$ was calculated as the difference between the sustained phase of the response and the baseline. Current values were normalized by the area of the insert $\left(0.6 \mathrm{~cm}^{2}\right)$ and results were expressed in $\mu \mathrm{A} / \mathrm{cm}^{2}$.

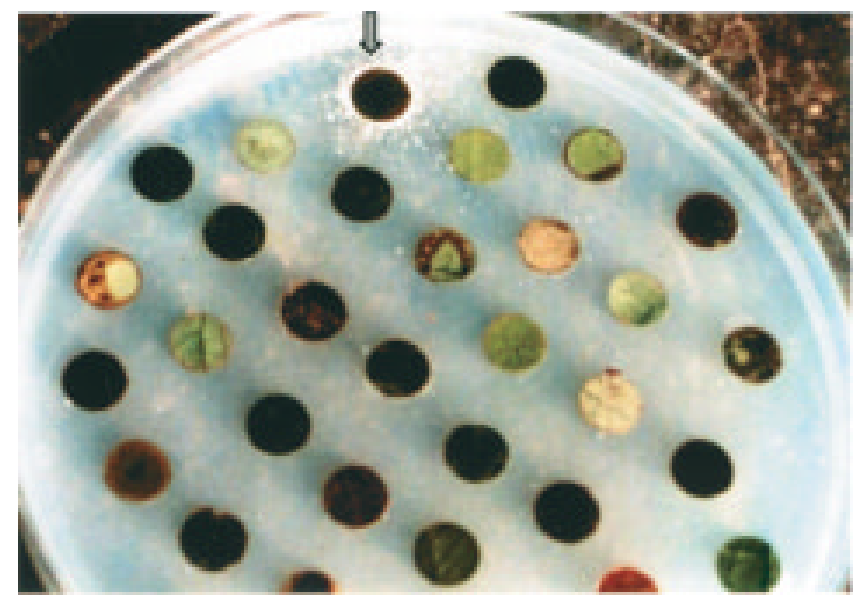

Fig. 2. Yeast two-hybrid assay. Leaf discs were placed on a lawn of YRG2- $\Delta$ F spread on Sc -Leu -Trp -His agar media supplemented with $1.5 \mathrm{mM}$ AT. The plate was incubated for 3 days at $30^{\circ} \mathrm{C}$. The arrow indicates growth of YRG2- $\Delta \mathrm{F}$ around the only leaf disc yielding a positive result among the samples tested in this plate (Trichilia sp. c.f. rubescens Oliv.).

\section{Results \\ Yeast Two-Hybrid Analysis Shows That CFTR NBD1 Forms Homodimers In Vivo and CF Mutations Affecting CFTR Processing Disrupt This Interaction}

Using the yeast two-hybrid system (29), we tested whether CFTR NBD1, in the absence of other CFTR domains, could form homodimers and thereby activate transcription of the HIS 3 reporter gene. CFTR NBDI and the upstream linker region between the first transmembrane domain and NBD l (aa residues 351-650) were fused in frame with the GAL4 activation domain (AD) and with the GAL4 DNA binding domain (BD), resulting in plasmids pADNBD 1 and pBDNBD 1, respectively. Cotransformation of the yeast strain YRG-2 with both plasmids (to produce YRG2-WT) conferred a HIS + phenotype to the yeast, indicating that NBDI is competent to form homodimers in vivo (Fig. 1). To assess the effect of CF-causing mutations on NBDI homodimerization, $\Delta \mathrm{I} 507, \Delta \mathrm{F} 508, \mathrm{~S} 549 \mathrm{R}$, and G55 ID were each introduced into NBD 1 in both pADNBDl and pBDNBDl. As shown in Figure $1 \mathrm{~B}$, the mutations $\Delta \mathrm{F} 508, \Delta \mathrm{I} 507$, and S549R, resulted in a HIS- phenotype, indicating defective NBD 1 dimerization. The CF-causing mutation G551D, which impairs chloride channel function, but not processing of CFTR, did not result in defective NBDl dimerization in yeast (Fig. 1).

Use of the Yeast Two-Hybrid System to Screen for Compounds That Restore NBD1AF508 Dimerization in Yeast

The results presented suggest that mutations in NBDI that affect CFTR processing are effectively modeled in yeast. Accordingly, we reasoned that a yeast strain containing derivatives of plasmids pADNBDl and pBDNBDl with the $\triangle$ F508 mutation 
A)

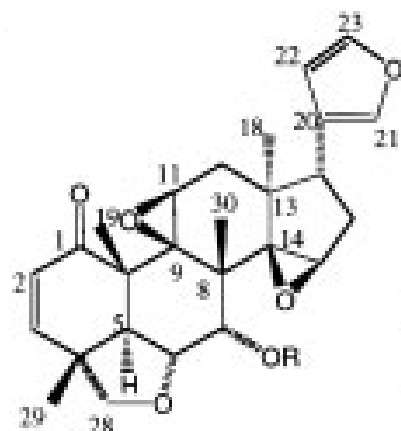

$\begin{array}{llll}\text { TS1 } & \mathrm{R}=\mathrm{H} & \stackrel{4}{\mathrm{C}} \mathrm{H}_{2} \mathrm{O} \\ \text { TS2 } & \mathrm{R}=\mathrm{H}_{3} \mathrm{C}-\underset{3}{\mathrm{C}}-\underset{2}{\mathrm{C}-}-\underset{\mathrm{I}^{*}}{\mathrm{C}-}-\end{array}$

B)

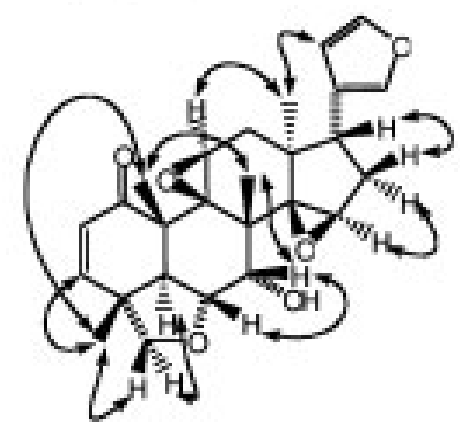

Fig. 3. Purified limonoid compounds from Trichilia sp. c.f. rubescens Oliv. (A) The structure and stereochemistry of TS 1 , TS2, and TS 3 were determined by analysis of the ${ }^{1} \mathrm{H}$ NMR spectra (Table 1), ${ }^{13} \mathrm{C}$ NMR spectra (Table 2), and IR spectra as described in Materials and Methods. (B) NOE's correlation of TS 1 .

(YRG2- $\Delta F$ ) would have potential as a drugscreening tool in the identification of new small molecules that restore mutant NBDI folding and/ or dimerization and promote growth of YRG2- $\Delta F$ on selective medium. As a source of diverse small molecules for drug screening, we investigated natural product compounds present in plants. Plants are rich in chemical diversity and are an established source of active pharmacologic compounds (30). Direct testing of plant leaf material using the yeast two-hybrid assay allowed large numbers of samples to be screened at a relatively low cost as compared to synthetic chemical libraries. A paper punch was used to sample plant leaves of approximately 600 different species within a segment of tropical rainforest in the Korup National Park of Cameroon. The plant leaf discs were placed in an array on a lawn of YRG2- $\Delta F$ yeast in a plate containing selective medium lacking histidine (Fig. 2). Small molecules within the plant discs diffused through the agar into the YRG2- $\Delta \mathrm{F}$ yeast strain, and compounds with activity to enhance the folding of mutant NBDl, or to enhance mutant NBD l dimerization, promoted growth of the yeast on selective medium lacking histidine. A plant of the genus Trichilia sp. c.f. rubescens Oliv. (Meliaceae) was identified as one of eight species testing positive in the bioassay (Fig. 2).

\section{Isolation of Novel Limonoid Compounds That Restore Dimerization to NBD1AF508}

Leaf material from Trichilia sp. c.f. rubescens Oliv. was fractionated using the YRG2- $\Delta \mathrm{F}$ bioassay to direct the purification of the active compound(s). Three structurally related limonoid compounds, designated TS1, TS2, and TS3, were subsequently purified and the structure of each determined by spectroscopic analysis including 2D NMR techniques, as described in Materials and Methods (Tables 1 and 2, Fig. 3). Each purified limonoid compound was tested using the YRG2- $\Delta$ F yeast strain (Fig. 4A) and also a control yeast strain in which the NBDl domain was absent from the GAL4 fusion construct (Fig. 4B). TS3 demonstrated a robust activity in the YRG2- $\Delta$ F yeast bioassay; comparatively lower activity was associated with TS2, and no activity was
A)

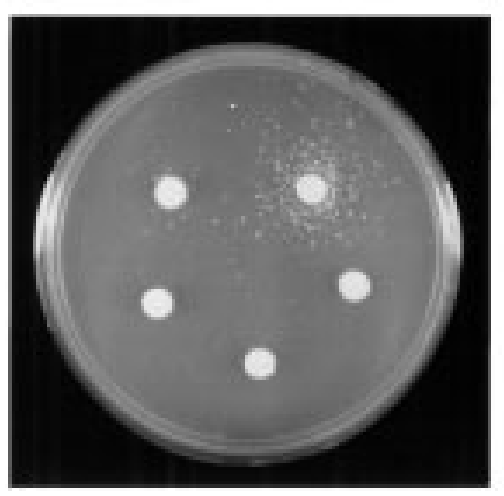

B)

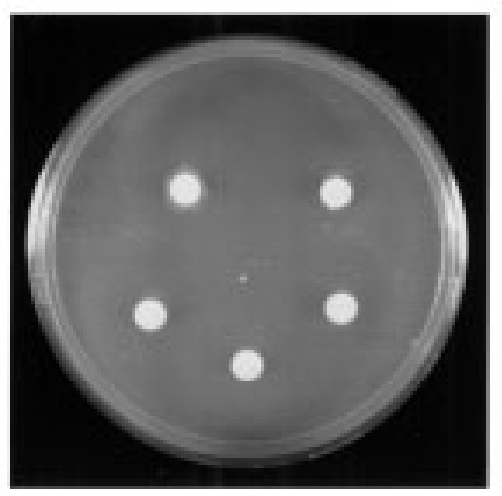

C)

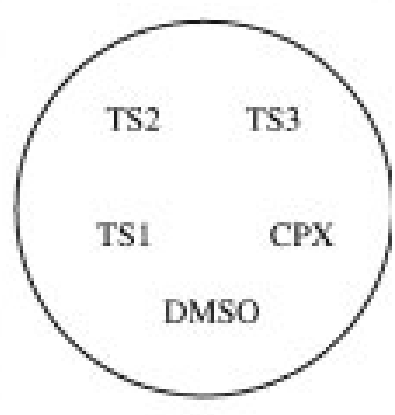

Fig. 4. Activity of the purified compounds TS1, TS2, and TS 3 on the yeast two-hybrid assay. $5 \times 10^{5}$ cells of the YRG2- $\Delta \mathrm{F}$ (A) or YRG-2 control strain (B) were spread over a selective -His -Leu -Trp plate, supplemented with 5 mM AT. Filter-paper discs containing $5 \mu \mathrm{l}$ of a $15 \mathrm{mM}$ stock solution of each compound in DMSO was placed on each plate at the position indicated in the diagram (C). Fifteen mM CPX and DMSO were used as controls. Plates were incubated for three days at $30^{\circ} \mathrm{C}$. 
detected for TS1 (Fig. 4A). CPX (8-cyclopentyl-1, 3-dipropylxanthine), a CFTR activator (31) shown to interact with NBDl of CFTR $\Delta$ F508 (32), did not present a detectable activity in the yeast bioassay (Fig. 4A). TS1, TS2, and TS3 did not promote growth of the control yeast strain (Fig. 4B), indicating that the effect of TS2 and TS 3 observed for YRG2- $-\mathrm{F}$ is mediated by the NBDs. TS2 and TS 3 also did not affect the growth of YRG2-WT (data not shown), however, wild-type NBDI dimerizes readily in this strain (resulting in a strong HIS + phenotype), which may have precluded detection of a growth effect mediated by these compounds. Although the mechanism of action of TS2 and TS 3 in correcting the YRG2- $\Delta \mathrm{F}$ growth defect is unknown, we hypothesized that these compounds could possibly act as chemical chaperones, interacting with and facilitating the folding of NBD $\triangle \mathrm{F} 508$ and restoring the NBD 1 interaction. The purified limonoids were therefore tested for rescue of the low chloride permeability defect presented by cells expressing CFTR $\Delta$ F508.

The Limonoid TS3 Is Effective in Increasing the Chloride Permeability of FRT Monolayers Expressing CFTRAF508

We tested the effect of TS1, TS2, and TS3 in correcting defective cAMP-stimulated chloride permeability in FRT cells stably expressing CFTR $\Delta$ F508 (FRT- $\Delta$ F). Treatment periods longer than $24 \mathrm{hr}$ are usually necessary for assessment of the efficacy of interventions designated to rescue the CFTR $\Delta$ F508 processing defect. Polarized FRT- $\Delta \mathrm{F}$ monolayers were incubated for $48 \mathrm{hr}$ in the presence of a range of concentrations of each limonoid compound to assess toxicity. TS2 was the most toxic of the three compounds, leading to decreased transepithelial resistance $\left(<170 \mathrm{Ohms} / \mathrm{cm}^{2}\right)$ of polarized FRT monolayers at concentrations higher than $2 \mu \mathrm{M}$. TS 1 and TS3 were toxic at concentrations higher than $10 \mu \mathrm{M}$. To test the effect of TS1, TS2, and TS 3 on the functional activity of CFTR $\Delta$ F508, monolayers of polarized FRT cells expressing CFTR $\Delta$ F508 (FRT- $\Delta$ F) were incubated in the presence of subtoxic concentrations of each compound for $48 \mathrm{hr}$ and the transepithelial chloride currents were assayed in Ussing chambers, following stimulation with cAMP agonists. In control experiments, FRT- $\Delta$ F monolayers were treated with equivalent concentration of DMSO. A low level of cAMP-stimulated chloride current was observed for the FRT- $\Delta$ F cell line, approximately $2.5 \mu \mathrm{A} / \mathrm{cm}^{2}$ (Fig. 5A). Treatment of FRT- $\Delta \mathrm{F}$ monolayers with $1-5 \mu \mathrm{M}$ TS 1 or $0.5-2 \mu \mathrm{M}$ TS2 was without effect on the cAMP-stimulated chloride currents (data not shown). Treatment of FRT- $\Delta \mathrm{F}$ monolayers for $48 \mathrm{hr}$ with 1 or $5 \mu \mathrm{M}$ TS 3 resulted in $38 \%$ and $27 \%$ increases, respectively, over DMSO-treated control monolayers (Fig. 5A). Longer incubation of monolayers with $5 \mu \mathrm{M}$ TS 3 for 48-72 hr gave similar results (data not shown). Thus TS3, the limonoid compound that had the greatest potency in correcting the growth defect of the YRG2- $\Delta$ F yeast strain, also had a significant effect in increasing the cAMP-stimulated chloride channel current of mammalian cells expressing CFTR $\Delta$ F508. TS3 had no effect on cAMP-stimulated chloride currents of FRT monolayers not expressing CFTR (Fig. 8).

To establish the duration of the TS3-mediated enhancement of CFTR $\Delta$ F508 chloride current following removal of the TS3 compound from treated cells ("wash out"), transepithelial currents were measured from TS3-treated monolayers after incubation in compound-free medium for increasing periods of time. As expected, prolonged incubation of TS3-treated monolayers in TS3-free growth medium $(24 \mathrm{hr})$ resulted in a gradual decrease of chloride current, down to control values (Fig. 5A). However, when monolayers were treated with $5 \mu \mathrm{M}$ TS3 for $48 \mathrm{hr}$ followed by removal of TS3 from the growth medium for only $9 \mathrm{hr}$, the cAMPstimulated chloride currents were increased to 1.8fold relative to control monolayers, a value greater than the $37 \%$ increase observed in the absence of the "wash out" (Fig. 5). These results indicate that enhancement of CAMP-stimulated chloride channel conductance by TS 3 is further increased by the removal of TS3 prior to measurements of chloride channel conductance.

\section{TS3 Has a Modest Effect in Increasing Chloride \\ Permeability of FRT Monolayers Expressing Wild-Type CFTR}

To determine if the effect of TS3 was specific to CFTR $\Delta$ F508, we incubated FRT monolayers stably expressing wild-type CFTR (FRT-WT) in the presence of $5 \mu \mathrm{M}$ TS 3 for $48 \mathrm{hr}$ and measured the cAMPactivated transepithelial chloride current. TS3 treatment increased the chloride current of monolayers expressing wild-type CFTR (CFTR wt) by 19\% over control monolayers (Fig. 6). Incubation of TS3treated FRT-WT monolayers in TS3-free medium for $9 \mathrm{hr}$ did not result in further increase of the chloride currents (Fig. 6).

\section{Effect of TS3 on CFTR and CFTRAF508 Chloride Channel Function}

Results in Figure 5 indicate that $5 \mu \mathrm{M}$ TS 3 could have a positive effect on CFTR $\Delta$ F508 processing and an inhibitory effect on chloride channel function. To directly test if TS 3 could inhibit CFTR channels, FRT- $\Delta$ F and FRT-WT polarized monolayers were incubated for $6 \mathrm{hr}$ in the presence of $5 \mu \mathrm{M}$ TS3, a period shorter than necessary to detect a possible rescue of the defective processing, but presumably sufficient to allow intracellular accumulation of TS3. The TS 3 treatment for $6 \mathrm{hr}$ resulted in a significant inhibition of the CFTR $\Delta$ F508 chloride currents, to $33 \%$ of the control (Fig. 7). The chloride currents of CFTR wt were inhibited to a lesser extent, to $79 \%$ of control. TS3 thus partially inhibited both CFTR wt and CFTR $\Delta$ F508 function when present 
A)

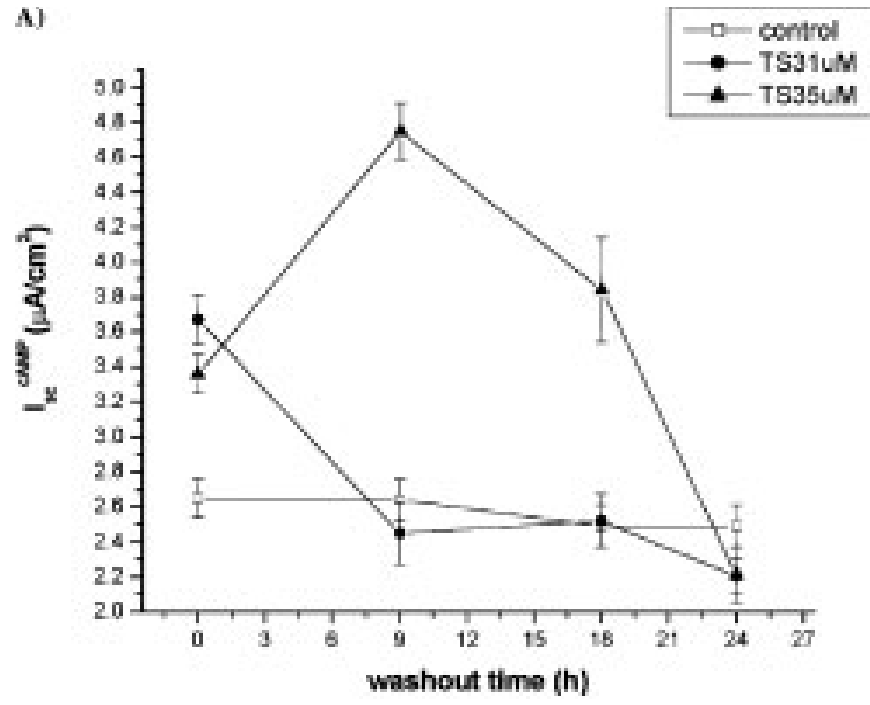

B) CFTRAFregs, centrol

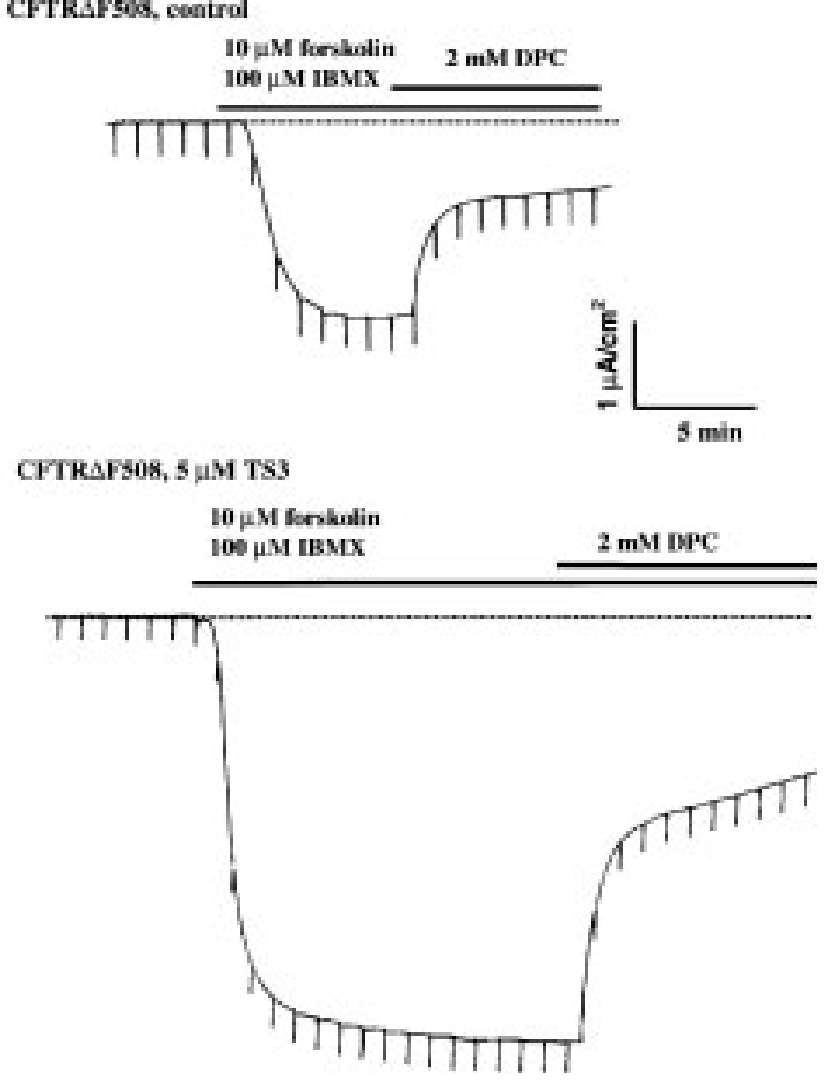

Fig. 5. Effect of TS3 on CFTR $\triangle$ F508 mediated cAMP-activated chloride current. (A) Polarized monolayers of FRT cells expressing CFTR $\triangle$ F508 were incubated for $48 \mathrm{hr}$ with TS3 (1 or $5 \mu \mathrm{M}$, as indicated) or the equivalent amount of DMSO. The monolayers were subsequently incubated in TS3-free growth medium for the time (hr) indicated, mounted in Ussing chambers, and transepithelial chloride currents were measured after activation with $10 \mu \mathrm{M}$ forskolin and $100 \mu \mathrm{M}$ IBMX. Results represent the mean \pm SEM for the number of experiments $(n)$ indicated. Five $\mu \mathrm{M}$ TS 3 treatment resulted in a significant difference from the respective control $(p<0.01$, two-tailed $t$-test) for wash out time points $0 \mathrm{hr}(n=4), 9 \mathrm{hr}(n=15)$, and $18 \mathrm{hr}(n=3)$. One $\mu \mathrm{M}$ TS 3 treatment resulted in a significant difference from the respective control $(p<0.01$, two-tailed $t$-test) for wash out time point 0 hr $(n=4)$. For all other time points $n=4$ (or greater). (B) Representative tracing for control and $5 \mu \mathrm{M}$ TS3-treated cells after $9 \mathrm{hr}$ of incubation in TS3-free growth medium. The bars indicate the presence of CAMP agonists (10 $\mu \mathrm{M}$ forskolin and $100 \mu \mathrm{M}$ IBMX) and CFTR inhibitor ( $2 \mathrm{mM}$ DPC). The dashed line represents the baseline current, before activation with cAMP agonists.

for a short incubation period that would preclude a possible positive effect on processing.

Addition of 5-15 $\mu \mathrm{M}$ TS3 directly to FRT- $\Delta \mathrm{F}$ monolayers mounted in Ussing chambers, either before or after stimulation with CAMP agonists, did not increase CFTR $\Delta$ F508 chloride current (data not shown), nor did a short incubation of FRT- $\Delta \mathrm{F}$ monolayers with TS3 for only $6 \mathrm{hr}$ (Fig. 7). These results, taken together with the results shown in Figure 5, suggest that the effect of TS 3 to increase chloride conductance of cells expressing CFTR $\triangle F 508$ is not immediate as observed with CFTR channel activators such as CPX and genistein (32-34), and is more likely to result in a time-dependent effect on CFTR processing rather than function. However, we were unable to detect in a Western blot an increase in the amount of the fully glycosylated form of CFTR $\Delta$ F508 in response to incubation of the cells with TS3 (data not shown), indicating that enhancement of processing by TS 3 is small.
TS3 Treatment Combined With Genistein Activation Effectively Rescues the Chloride Impermeability of FRT- $\Delta F$

Genistein is an activator of CFTR that has been shown to increase the open time probability $P_{\mathrm{o}}$ of the CFTR $\Delta$ F508 channel $(13,18,35)$. The presence of $50 \mu \mathrm{M}$ of genistein during chloride channel activation significantly enhances chloride currents of DMSOand TS3-treated FRT- $\Delta \mathrm{F}$ monolayers by $100 \%$ and $51 \%$, respectively (Fig. 8). A 3-fold increase in chloride channel conductance in FRT- $\Delta \mathrm{F}$ cells is obtained when $50 \mu \mathrm{M}$ of genistein is used to activate TS3treated monolayers (Fig. 8). The effects of TS3 and genistein are thus additive, suggesting that enhanced restoration of CFTR $\Delta$ F508 functional activity can be attained with the use of small molecules having complementary effects in restoring CFTR $\Delta$ F508 processing and function. Furthermore, the magnitude of the CFTR $\Delta$ F508 chloride current increase resulting from $5 \mu \mathrm{M}$ TS3 treatment was similar to the effect of activation with $50 \mu \mathrm{M}$ genistein alone (Fig. 8). 


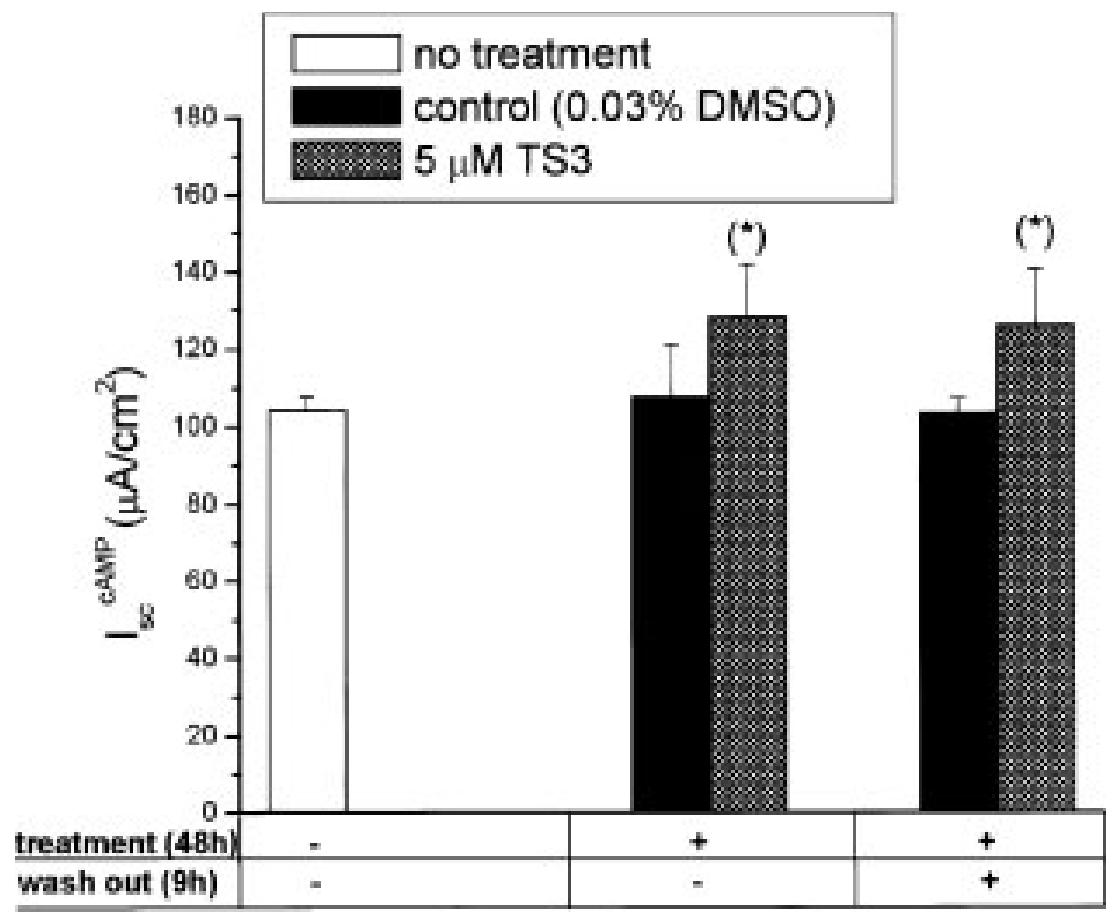

Fig. 6. Effect of TS3 on wildtype CFTR mediated cAMP activated chloride current. Polarized monolayers of FRT cells expressing CFTR wt (FRT-WT) were incubated for 48 hours with $5 \mu \mathrm{M}$ TS 3 or the equivalent amount of DMSO (control). In some experiments, the monolayers were subsequently incubated for 9 hours in TS3-free growth medium. Monolayers were mounted in Ussing chambers and transepithelial chloride currents were measured after activation with $10 \mu \mathrm{M}$ forskolin and 100 $\mu$ M IBMX. Results represent the mean \pm SEM of $n=6$ experiments. The asterisk indicates that the TS 3 treatment resulted in a significant difference from the respective control $(p<0.05$, two-tailed $t$-test $)$.

\section{Discussion}

The molecular basis for the effect of the $\Delta$ F508 mutation on CFTR processing is unknown, although it is generally accepted that the mutation causes misfolding of the CFTR $\Delta$ F508 polypeptide within the ER (36), resulting in retention and degradation by the ER-associated quality control mechanism (37) and substantially reduced levels of CFTR $\Delta$ F508 at the plasma membrane. CFTR $\Delta$ F508 that is correctly located at the plasma membrane has decreased stability in relation to CFTR wt (38-40); however, the mutant protein still retains at least one-third of the chloride channel activity of wild-type CFTR (14).

Using the yeast two-hybrid system, we have determined that CFTR NBDl forms dimers in vivo in yeast and that $\Delta$ F508 impairs the ability of NBD 1 to

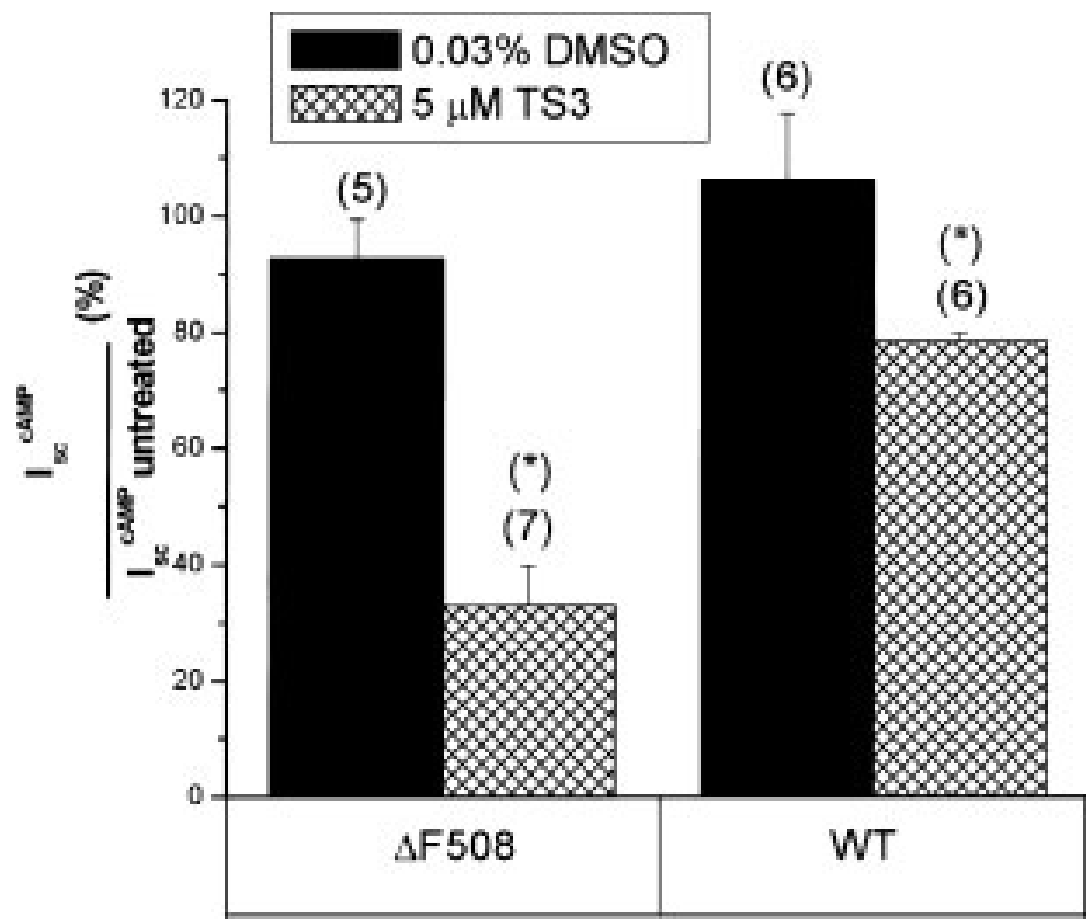

Fig. 7. Effect of short-term TS3 treatment of cells on CAMP activated chloride channel function of CFTR $\Delta$ F508 or wildtype CFTR. Polarized monolayers of FRT- $\Delta \mathrm{F}$ cells expressing CFTR $\Delta$ F508 ( $\Delta$ F508) or FRT-WT cells expressing CFTR wt (WT) were incubated for 6 hours with $5 \mu \mathrm{M}$ TS 3 or the equivalent amount of DMSO $(0.03 \%)$. Monolayers were mounted in Ussing chambers and transepithelial chloride currents were measured after activation with $10 \mu \mathrm{M}$ forskolin and $100 \mu \mathrm{M}$ IBMX. The maximal cAMP-stimulated chloride conductance observed for untreated FRT-WT monolayers was $85 \mu \mathrm{A} / \mathrm{cm}^{2}$. Results are expressed as percentage of currents for untreated monolayers and represent the mean \pm SEM for the indicated number of experiments $(n)$. The asterisk indicates that the TS3 treatment resulted in a significant difference from the respective control $(p<0.05$, two-tailed $t$-test). 


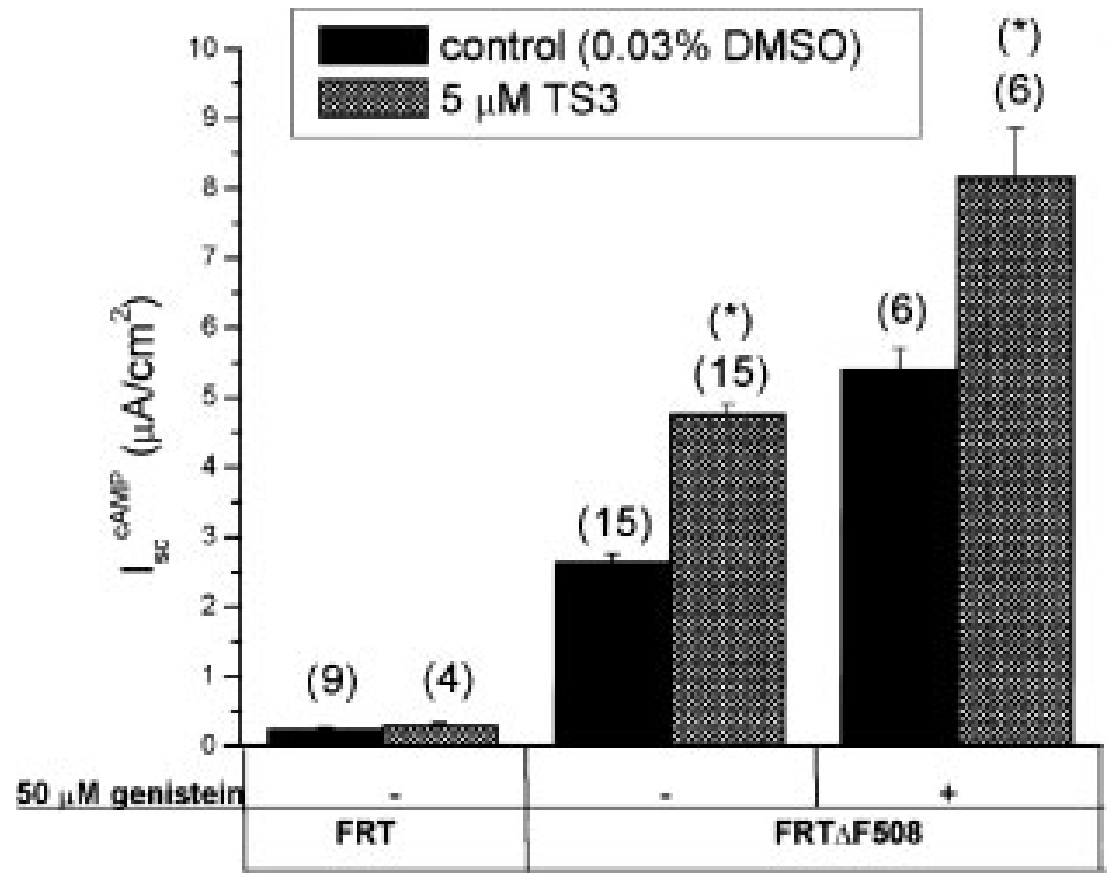

Fig. 8. The combined effect of TS3 and genistein to increase CFTR $\Delta$ F508 cAMPactivated chloride current. Polarized monolayers of FRT cells (FRT) or FRT- $\Delta$ F cells expressing CFTR $\Delta$ F508 (FRT- $\Delta$ F508) were incubated for 48 hours with $5 \mu \mathrm{M}$ TS 3 or the equivalent amount of DMSO and subsequently incubated for 9 hours in TS3-free growth medium. Monolayers were mounted in Ussing chambers and transepithelial chloride currents were measured after activation with $10 \mu \mathrm{M}$ forskolin and $100 \mu \mathrm{M}$ IBMX or with $50 \mu \mathrm{M}$ genistein followed by $10 \mu \mathrm{M}$ forskolin and $100 \mu \mathrm{M}$ IBMX, as indicated. Results represent the mean \pm SEM for the indicated number of experiments $(n)$. The asterisks indicate that TS3 treatment resulted in a significant increase in chloride current ( $p<0.01$, two-tailed $t$-test). form dimers. Because dimerization of NBDs has been demonstrated for several other ABC transporters $(22,25,26,41-43)$, the dimerization of NBD 1 that we observe in yeast may represent a bona fide interaction between NBDl domains of CFTR molecules that occurs in vivo in mammalian cells during the normal processing of CFTR. The quaternary structure of CFTR is currently a subject of debate, although previous experiments have suggested that CFTR is a monomer (44). Recently, however, it has been shown that CFTR has the appearance of dimers at the plasma membrane (45) and in reconstituted liposomes (46). Dimerization has also been shown to regulate CFTR functional activity (47). The dimeric form may thus be transient and represent only a fraction of the CFTR within the cell.

Our results indicate that CFTR processing is associated with folding of wild-type NBDI into a structure that is competent to form homodimers. CF mutations affecting CFTR processing ( $\Delta$ F508, $\Delta$ I507, and S549R) resulted in defective CFTR NBD 1 dimer formation in yeast. In contrast, the G551D mutation, which does not impair CFTR processing, had no effect on NBDl association. The correlation between mutations causing defective processing of CFTR and defective dimerization of NBD 1 in yeast further suggests that dimerization of CFTR, mediated in part by NBD 1, could be associated with CFTR processing. Alternatively, it is possible that NBD 1 dimer formation is a property of NBDl that has folded into a native state, thereby becoming competent to selfassociate. Interestingly, dimerization of the NBD domains of peroxisomal $\mathrm{ABC}$ "half-transporters" have also been shown in the yeast two-hybrid system, and dimerization was disrupted by two mutations associated with X-linked adrenoleukodystrophy (43). Homodimerization of NBD 1 in yeast could be a consequence of the absence of NBD2 because allosteric interaction between NBD1 and NBD2 has been observed (48). However, interaction between NBD 1 and NBD2 using the yeast two-hybrid system has not been observed (49).

Although the biological significance of CFTR NBD l dimerization in vivo is unknown, the yeast two-hybrid assay provides a means to assay a growth-defective phenotype for a CF-causing mutation in yeast, and to detect the activity of bioactive small molecules that reverse the growth defect. We have used this assay to screen a biodiverse collection of tropical plants. Bioassay-directed fractionation from Trichilia sp. c.f. rubescens Oliv. yielded a pure limonoid compound TS3 with activity to correct the growth defect of YRG2- $\Delta \mathrm{F}$. Limonoids are a group of highly oxidized terpenoids present in several species of the genus Trichilia (50-57). Several biological activities have been shown for limonoid compounds: insect antifeedant (58-60), inhibition of cell adhesion (61), toxicity to DNA repair deficient yeast (62), and antimicrobial activity (63). Possibly other limonoids from related Trichilia species or derivatives of TS3 have activity to correct the $\Delta$ F508 defect. Because TS3 demonstrated activity to correct both the $\Delta$ F508 growth defect in yeast and also the chloride permeability defect in FRT- $\Delta \mathrm{F}$ cells, the results strongly suggest that the effect of the $\Delta$ F508 mutation on NBDl is effectively modeled in yeast, and that activity of compounds to correct the molecular defect may be assayed using the yeast two-hybrid system. 
Enhancement of CFTR $\Delta$ F508 chloride current by TS3 treatment was increased when the cells were incubated in TS3-free medium prior to measurement of chloride conductance. These results lead us to hypothesize that increased chloride conductance resulting from a putative positive effect of TS3 to increase CFTR $\Delta$ F508 levels at the plasma membrane may be countered by an inhibitory effect of TS3 on CFTR $\Delta$ F508 function. In support of this notion, an inhibitory effect of TS3 was also noted when FRT- $\Delta \mathrm{F}$ monolayers were incubated with $5 \mu \mathrm{M}$ TS 3 for $6 \mathrm{hr}$. We did not observe enhancement of CFTR $\Delta$ F508 chloride current in CFTR cells expressing CFTR $\Delta$ F508 when cells were incubated with limonoid compounds TS1 or TS2. As shown in Figure $3 \mathrm{~A}$, these compounds differ from TS 3 only with respect to the functional group associated with C7 position, which is hydrogen in TS3. This suggests that the activity of TS3 to correct the NBD 1 dimerization defect in yeast and also the activity to enhance chloride conductance from cells expressing CFTR $\Delta$ F508 depends at least in part on the structural determinants presented at C7.

TS3-mediated increase in FRT- $\Delta \mathrm{F}$ chloride currents required that monolayers were incubated for at least $48 \mathrm{hr}$ with TS3, consistent with the time required to detect the functional activity associated with an increase in processed CFTR $\Delta$ F508. In contrast, short incubations of FRT- $\Delta$ F cells with TS 3 for periods of $6 \mathrm{hr}$ or less did not result in a TS3mediated increase in FRT- $\Delta \mathrm{F}$ chloride current. The TS3 compound therefore does not appear to activate CFTR $\triangle$ F508 in the same manner as genistein or CPX, which induce a rapid increase in the functional activity of CFTR $\Delta$ F508 already localized at the plasma membrane. Instead, TS 3 most likely promotes an increase of CFTR $\Delta$ F508 channels at the plasma membrane, detectable as an increase in cAMP-stimulated chloride currents, which could result from improved processing at the ER or increased stability of the small fraction of the mutant protein present at the plasma membrane. A TS3-mediated increase in the amount of processed CFTR $\Delta \mathrm{F} 508$ at the plasma membrane was not detected by Western blot analysis, suggesting that the effect of TS3 to correct processing is small. However, in analogous studies involving treatment of MDCK cells expressing CFTR $\Delta$ F508 with the anticancer drug doxorubicin, it was similarly observed that a drug-mediated increase in cAMP-stimulated chloride channel activity (64) corresponded to only a small improvement of CFTR $\Delta$ F508 processing, which was not readily detectable by Western blot analysis.

It has been estimated that $10 \%$ of wild-type CFTR activity can rescue the electrolyte defect in a CF tissue (65), representing roughly a 10 -fold increase in CFTR $\Delta$ F508-mediated chloride permeability. TS3 did not mediate this level of rescue of CFTR $\Delta \mathrm{F} 508$; however, a 3-fold increase in the cAMP-stimulated chloride current in FRT cells expressing CFTR $\Delta$ F508 was attained by treatment with both genistein and TS3.
An effective strategy to increase CFTR $\Delta$ F508 chloride conductance may thus involve a combination of small molecules that are active in rescuing CFTR $\Delta$ F508 processing and functional defects. TS 3 represents a novel class of compounds that can interact with NBDl $\triangle \mathrm{F} 508$ in vivo and promote an increase in cAMPstimulated chloride permeability of cells expressing CFTR $\Delta 508$. The yeast two-hybrid assay described here provides a means to identify additional new small molecules that target NBDI and have activity to increase the chloride permeability of cells expressing CFTR 4 F508.

\section{Acknowledgments}

We are grateful to the members of the African International Cooperative in Biodiversity Group (ICBG) and the Smithsonian Institute for Tropical Research, especially Liz Losos, Duncan Thomas, Sainge Moses, Mambo Peter, Rodney Stubina, and David Kenfack, for their invaluable help during plant collection and identification. This study was supported by the ICBG "Drug Development and Conservation in West and Central Africa" Grant No TW01023-01-AP2 from the Fogarty Center, NIH, and Grant No CAM:02 from the International Science Program (ISP), Uppsala University, Sweden.

\section{References}

1. Riordan JR, Rommens JM, Kerem B, et al. (1989) Identification of the cystic fibrosis gene: cloning and characterization of complementary DNA [published erratum appears in Science (1989) 245:1437]. Science 245: 1066-1073.

2. Rommens JM, Iannuzzi MC, Kerem B, et al. (1989) Identification of the cystic fibrosis gene: chromosome walking and jumping. Science 245: 1059-1065.

3. Welsh MJ, Smith AE. (1993) Molecular mechanisms of CFTR chloride channel dysfunction in cystic fibrosis. Cell 73:12511254.

4. Sheppard DN, Welsh MJ. (1999) Structure and function of the CFTR chloride channel. Physiol. Rev. 79(suppl 1): S23-S45.

5. Holland IB, Blight MA. (1999) ABC-ATPases, adaptable energy generators fuelling transmembrane movement of a variety of molecules in organisms from bacteria to humans. J. Mol. Biol. 293: 381-399.

6. Higgins CF. (1992) ABC transporters: From microorganisms to man. Annu. Rev. Cell Biol. 8: 67-113.

7. Jensen TJ, Loo MA, Pind S, Williams DB, Goldberg AL, Riordan JR. (1995) Multiple proteolytic systems, including the proteasome, contribute to CFTR processing. Cell 83: 129135.

8. Lukacs GL, Mohamed A, Kartner N, Chang XB, Riordan JR, Grinstein S. (1994) Conformational maturation of CFTR but not its mutant counterpart (delta F508) occurs in the endoplasmic reticulum and requires ATP. Embo. J. 13: 6076-6086.

9. Meacham GC, Patterson C, Zhang W, Younger JM, Cyr DM. (2001) The Hsc70 co-chaperone CHIP targets immature CFTR for proteasomal degradation. Nat. Cell Biol. 3: 100-105.

10. Pind S, Riordan JR, Williams DB. (1994) Participation of the endoplasmic reticulum chaperone calnexin (p88, IP90) in the biogenesis of the cystic fibrosis transmembrane conductance regulator. J. Biol. Chem. 269: 12784-12788.

11. Ward CL, Omura S, Kopito RR. (1995) Degradation of CFTR by the ubiquitin-proteasome pathway. Cell 83: 121-127.

12. Haws CM, Nepomuceno IB, Krouse ME, Wakelee H, Law T, Xia Y, Nguyen Y, Wine JJ. (1996) Delta F508-CFTR channels: 
kinetics, activation by forskolin, and potentiation by xanthines. Am. J. Physiol. 270: C1544-C1555.

13. Hwang TC, Wang F, Yang IC, Reenstra WW. (1997) Genistein potentiates wild-type and delta F508-CFTR channel activity. Am. J. Physiol. 273: C988-C998.

14. Dalemans W, Barbry P, Champigny G, et al. (1991) Altered chloride ion channel kinetics associated with the delta F508 cystic fibrosis mutation [see comments]. Nature 354: 526-528.

15. Sato S, Ward CL, Krouse ME, Wine JJ, Kopito RR. (1996) Glycerol reverses the misfolding phenotype of the most common cystic fibrosis mutation. J. Biol. Chem. 271: 635-638.

16. Brown CR, Hong-Brown LQ, Biwersi J, Verkman AS, Welch WJ. (1996) Chemical chaperones correct the mutant phenotype of the delta F508 cystic fibrosis transmembrane conductance regulator protein. Cell Stress Chaperones 1: 117-125.

17. Denning GM, Anderson MP, Amara JF, Marshall J, Smith AE, Welsh MJ. (1992) Processing of mutant cystic fibrosis transmembrane conductance regulator is temperature-sensitive [see comments]. Nature 358: 761-764.

18. Hwang TC, Sheppard DN. (1999) Molecular pharmacology of the CFTR Cl- channel. Trends Pharmacol. Sci. 20: 448-453.

19. Schultz BD, Singh AK, Devor DC, Bridges RJ. (1999) Pharmacology of CFTR chloride channel activity. Physiol. Rev. 79(suppl 1): S109-S144.

20. Cheng SH, Gregory RJ, Marshall J, Paul S, Souza DW, White GA, O'Riordan CR, Smith AE. (1990) Defective intracellular transport and processing of CFTR is the molecular basis of most cystic fibrosis. Cell 63: 827-834.

21. Thomas PJ, Pedersen PL. (1993) Effects of the delta F508 mutation on the structure, function, and folding of the first nucleotide-binding domain of CFTR. J. Bioenerg. Biomembr. 25: 11-19.

22. Kennedy KA, Traxler B. (1999) MalK forms a dimer independent of its assembly into the MalFGK2 ATP-binding cassette transporter of Escherichia coli. J. Biol. Chem. 274: 6259-6264.

23. Nikaido K, Liu PQ, Ames GF. (1997) Purification and characterization of HisP, the ATP-binding subunit of a traffic ATPase (ABC transporter), the histidine permease of Salmonella typhimurium. Solubility, dimerization, and ATPase activity. J. Biol. Chem. 272: 27745-27752.

24. Liu P-Q, Ames GF-L. (1998) In vitro disassembly and reassembly of an $\mathrm{ABC}$ transporter, the histidine permease. Proc. Natl. Acad. Sci. U.S.A. 95: 3495-3500.

25. Hung LW, Wang IX, Nikaido K, Liu PQ, Ames GF, Kim SH. (1998) Crystal structure of the ATP-binding subunit of an ABC transporter [see comments]. Nature 396: 703-707.

26. Lapinski PE, Miller GG, Tampe R, Raghavan M. (2000) Pairing of the nucleotide binding domains of the transporter associated with antigen processing. J. Biol. Chem. 275: 68316840.

27. Jolad SD, Hoffmann JJ, Schram KH, Cole JR, Tempesta MS. (1981) Constituents of Trichilia hispida (Meliaceae). 3. Structures of the cytotoxic limonoids: Hispidins A, B, C. J. Org. Chem. 46: 641-644.

28. Sheppard DN, Carson MR, Ostedgaard LS, Denning GM, Welsh MJ. (1994) Expression of cystic fibrosis transmembrane conductance regulator in a model epithelium. Am. J. Physiol. 266: L405-L413.

29. Fields S, Song O. (1989) A novel genetic system to detect protein-protein interactions. Nature 340: 245-246.

30. Simmonds MSJ, Grayer R. (1999) Drug discovery and development. In Walton NJ, Brown DE, eds. Chemicals from Plants: Perspectives on Plant Secondary Products. River Edge, NJ: Imperial College Press; 215-249.

31. Eidelman O, Guay-Broder C, van Galen PJ, et al. (1992) Al adenosine-receptor antagonists activate chloride efflux from cystic fibrosis cells. Proc. Natl. Acad. Sci. U.S.A. 89: 5562-5566.

32. Cohen BE, Lee G, Jacobson KA, et al. (1997) 8-Cyclopentyl1,3-dipropylxanthine and other xanthines differentially bind to the wild-type and delta F508 first nucleotide binding fold (NBF-1) domains of the cystic fibrosis transmembrane conductance regulator. Biochemistry 36: 6455-6461.
33. He Z, Raman S, Guo Y, Reenstra WW. (1998) Cystic fibrosis transmembrane conductance regulator activation by cAMPindependent mechanisms. Am. J. Physiol. 275: C958-C966.

34. Al-Nakkash L, Hwang TC. (1999) Activation of wild-type and deltaF508-CFTR by phosphodiesterase inhibitors through cAMP-dependent and -independent mechanisms. Pflugers Arch. 437: 553-561.

35. Wang F, Zeltwanger S, Hu S, Hwang TC. (2000) Deletion of phenylalanine 508 causes attenuated phosphorylationdependent activation of CFTR chloride channels. J. Physiol. (Lond) 524: 637-648.

36. Zhang F, Kartner N, Lukacs GL. (1998) Limited proteolysis as a probe for arrested conformational maturation of delta F508 CFTR [see comments]. Nat. Struct. Biol. 5: 180-183.

37. Kopito RR. (1999) Biosynthesis and degradation of CFTR. Physiol. Rev. 79(suppl 1): S167-S173.

38. Lukacs GL, Chang XB, Bear C, et al. (1993) The delta F508 mutation decreases the stability of cystic fibrosis transmembrane conductance regulator in the plasma membrane. Determination of functional half-lives on transfected cells. J. Biol. Chem. 268: 21592-21598.

39. Heda GD, Tanwani M, Marino CR. (2001) The Delta F508 mutation shortens the biochemical half-life of plasma membrane CFTR in polarized epithelial cells. Am. J. Physiol. Cell. Physiol. 280: C166-C174.

40. Sharma M, Benharouga M, Hu W, Lukacs GL. (2001) Conformational and temperature-sensitive stability defects of the delta F508 cystic fibrosis transmembrane conductance regulator in post-endoplasmic reticulum compartments. J. Biol. Chem. 276: 8942-8950.

41. Yaan Y, Blecker S, Martsinkevieh O, Miften L, Thomas P, Hant J. (2001) The crystal structure of the MJO796 ATPbinding cassette. Implications for the structural consequences of ATP hydrolysis in the active site of an $\mathrm{ABC}$ transporter. J. Biol. Chem. 276: 32313-21.

42. Hopfner KP, Karcher A, Shin DS, et al. (2000) Structural biology of Rad50 ATPase: ATP-driven conformational control in DNA double-strand break repair and the ABC-ATPase superfamily. Cell 101: 789-800.

43. Liu LX, Janvier K, Berteaux-Lecellier V, Cartier N, Benarous R, Aubourg P. (1999) Homo- and heterodimerization of peroxisomal ATP-binding cassette half-transporters. J. Biol. Chem 274: 32738-32743.

44. Marshall J, Fang S, Ostedgaard LS, et al. (1994) Stoichiometry of recombinant cystic fibrosis transmembrane conductance regulator in epithelial cells and its functional reconstitution into cells in vitro. J. Biol. Chem. 269: 2987-2995.

45. Eskandari S, Wright EM, Kreman M, Starace DM, Zampighi GA. (1998) Structural analysis of cloned plasma membrane proteins by freeze-fracture electron microscopy. Proc. Natl. Acad. Sci. U.S.A. 95: 11235-11240.

46. Ramjeesingh M, Li C, Kogan I, Wang Y, Huan LJ, Bear CE. (2001) A monomer is the minimum functional unit required for channel and ATPase activity of the cystic fibrosis transmembrane conductance regulator. Biochemistry 40: 1070010706.

47. Wang S, Yue H, Derin RB, Guggino WB, Li M. (2000) Accessory protein facilitated CFTR-CFTR interaction, a molecular mechanism to potentiate the chloride channel activity. Cell 103: 169-179.

48. Ramjeesingh M, Li C, Garami E, et al. (1999) Walker mutations reveal loose relationship between catalytic and channelgating activities of purified CFTR (cystic fibrosis transmembrane conductance regulator). Biochemistry 38: 14631468.

49. Taylor JC, Horvath AR, Higgins CF, Begley GS. (2001) The multidrug resistance p-glycoprotein. Oligomeric state and intramolecular interactions. J. Biol. Chem. 276: 36075-36078.

50. Cortez DA, Fernandes JB, Vieira PC, da Silva MF, Ferreira AG. (2000) A limonoid from Trichilia estipulata. Phytochemistry 55: 711-713.

51. Connolly JD, Labbe C, Rycroft DS, Okorie DA, Taylor DAH. (1979) Tetranortriterpenoids and related compounds. Part 23. 
Complex tetranortriterpenoids from Trichilia prieuriana and Guarea thompsonii (Meliaceae), and the hydrolysis products of drageanin, prieurianin, and related compounds. J. Chem. Res. Synop. 1979: 256-257.

52. Arenas C, Rodriguez-Hahn L. (1990) Limonoids from Trichilia havanensis. Phytochemistry 29: 2953-2956.

53. Garcez FR, Garcez WS, Tsutsumi MT, Roque NF. (1997) Limonoids from Trichilia elegans ssp. Phytochemistry 45: 141148.

54. Inada A, Konishi M, Murata H, Nakanishi T. (1994) Structures of a new limonoid and a new triterpenoid derivative from pericarps of Trichilia connaroides. J. Nat. Prod. 57: 14461449.

55. Olugbade TA, Adesanya SA. (2000) Prieurianoside, a protolimonoid glucoside from the leaves of Trichilia prieuriana. Phytochemistry 54: 867-870.

56. Rodriguez-Hahn L, Cardenas J, Arenas C. (1996) Trichavesin, a prieurianin derivative from Trichilia havanensis. Phytochemistry 43: 457-459.

57. Taylor DAH. (1982) A new structural proposal for the tetranortriterpenoid dregeanin. J. Chem. Res. Synop. 1982: 55.

58. Nakanishi K. (1982) Recent studies on bioactive compounds from plants. J. Nat. Prod. 45: 15-26.
59. Nakatani $M$, Okamoto $M$, Iwashita $T$, Miuzukawa $K$, Naoki $\mathrm{H}$, Hase T. (1984) Isolation and structures of three secolimonoids, insect antifeedants from Trichilia roka (Meliaceae). Heterocycles 22: 2335-2340.

60. Nakatani M, Iwashita T, Naoki H, Hase T. (1985) Structure of a limonoid antifeedant from Trichilia roka. Phytochemistry 24: 195-196.

61. Musza LL, Killar LM, Speight S, et al. (1994) Potent new cell adhesion inhibitory compounds from the root of Trichilia rubra. Tetrahedron 50: 11369-11378.

62. Gunatilaka AA, Bolzani V, Dagne E, et al. (1998) Limonoids showing selective toxicity to DNA repair-deficient yeast and other constituents of Trichilia emetica. J. Nat. Prod. 61: 179-184.

63. Aladesanmi AJ, Odediran SA. (2000) Antimicrobial activity of Trichilia heudelotti leaves. Fitoterapia 71: 179-182.

64. Maitra R, Shaw CM, Stanton BA, Hamilton JW. (2001) Increased functional cell surface expression of CFTR and DeltaF508-CFTR by the anthracycline doxorubicin. Am. J. Physiol. Cell Physiol. 280: C1031-C1037.

65. Johnson LG, Olsen JC, Sarkadi B, Moore KL, Swanstrom R, Boucher RC. (1992) Efficiency of gene transfer for restoration of normal airway epithelial function in cystic fibrosis. Nat. Genet. 2: 21-25. 